\title{
The Relationship of Anxiety with Adjustment and Procrastination in Female High School Students
}

\author{
Hossein Jenaabadi* \\ Saeed Vali Rooh \\ Hamid Reza Khods \\ Hassan Hajiabadi

\begin{abstract}
*Associate professor, Department of Educational Sciences and Psychology
\end{abstract} \\ University of Sistan and Baluchestan, University of Farhangian Zahedan, Iran; hjenaabadi@ped.usb.ac.ir
}

\author{
Doi:10.5901/mjss.2016.v7n2s2p66
}

\section{Abstract}

The objective of the current study was to examine the relationship of test anxiety with adjustment and procrastination in female high school students in Zahedan. This was a descriptive-correlational study. The statistical population of this study included 4000 female high school students in Zahedan, among whom the sample was selected through applying multistage cluster sampling method. The data collection tools were three questionnaires containing Beck Anxiety Inventory (BAI), Adjustment Inventory of High School Students (AISS), and the Savari Academic Procrastination Scale (2011). Both descriptive and inferential statistics, including Pearson correlation coefficient, were used to analyze the obtained data. The results of Pearson correlation coefficient indicated that anxiety among students was significantly and directly correlated with adjustment and its dimensions (including emotional adjustment, social adjustment, and educational adjustment). Additionally, anxiety among students was significantly and directly related to procrastination and its dimensions (including intentional procrastination, procrastination resulting from physical-mental fatigue, and procrastination caused by disorganization).

Keywords: Anxiety, Adjustment, Procrastination, High School Students.

\section{Introduction}

Maslow (2000) believed that when a person feels a sense of inner respect and/or respects himself/herself, he/she experiences feelings of inner security and self-confidence and feels that he/she is valuable and worthy. In contrast, when a person considers no respect for himself/herself, in the face of life, he/she feels humiliation, frustration and inability. To achieve a sense of self-respect, one should know himself/herself well and be compatible in order to clearly and accurately distinguish his/her virtues and weaknesses. If these requirements are met, then human's most significant need, i.e. the need for self-realization, will be fulfilled and one can achieve his/her highest potential. To treat people with low selfesteem in an outpatient clinic, Pope et al. (1999) applied cognitive behavioral methods and obtained outstanding results. In addition, these methods were carried out on talented and gifted students, who had completely negative attitudes towards themselves, and positive results were achieved. When dealing with children and adolescents at schools and students in universities, hospitals, social service centers, and private clinics, conducting such programs is highly recommended. Generally, the concept of adjustment was adapted from biology. In biology, this term refers to adaption and is considered as a set of activities that one can do to coordinate with changes in the environment. As an instance, a person's conformity with environmental changes can be regarded as an example of adjustment. However, from the psychological point of view, adjustment is considered as a physiological process based on which an individual can confront with or handle his/her desires (tendencies) and everyday life challenges.

Procrastination steals time, makes a person feel guilty and changes others' opinion about that person. Procrastination is the action of postponing doing something and referring it to the future (Sutton, 2009). From a psychological standpoint, procrastination means delegating a work that one has decided to do to the future which is an undesirable and inappropriate behavior that gradually becomes a habit (Alice, 1996, translated by: Farjad, 2003).

Anxiety is defined as a concern caused by an anticipated problem and usually refers to a danger in the future. Although anxiety can be helpful in identifying future risks and planning for confronting with them, excessive anxiety is 
harmful (Kring et al., 2007, translated by: Shamsipour, 2012). Negative emotions, such as anxiety and the like, are not created due to the events; however, they are created as a result of people's expectations and interpretations of those event. In everyday life, there are numerous situations that are objectively dangerous. In this regard, Beck (1976) argued that in cases of anxiety, people usually overestimate the risk of a specific situation. These overestimations automatically and involuntarily activate "the anxiety program" (Hawton et al., 1989, translated by: Ghasemzadeh, 2012).

According to what was mentioned earlier, it can be noticed that when unpleasant thoughts occupy adolescents' minds, they become too upset in terms of mental disorders, and their ability to confront with the issue dramatically decreases. This leads to procrastination and lack of adjustment with the situation. Nowadays, evaluation of students' mental health is considered as one of the most important aspects of mental health. Evidence confirms that organizing mental health services at schools is the main strategy for improving the mental health of students and ultimately the entire society (Sadeghian et al., 2010).

Vodanovich and Rupp (1999), in a study, indicated that students with high levels of procrastination significantly obtained higher scores on boredom. In addition, students with high procrastination significantly gained higher scores on external stimulation, internal stimulation, emotional responses, and time perception.

In another study, Essau, Ederer, Ocallaghan, and Ashemann (2008) demonstrated that higher levels of procrastination made students unable to set and/or organize their educational goals. This leads to depression, anxiety, and stress.

Tozandehjani et al. (2007), in a study aimed to examine the relative effectiveness of cognitive-behavioral and selfesteem trainings on social adjustment of third grade male high school students, showed the effectiveness of cognitivebehavioral trainings on students' social adjustment and self-esteem. However, these trainings, considering the subjects' demographic characteristics, had no significant relationships with students' social adjustment and self-esteem. Other words, with regard to the subjects' personal traits, self-esteem trainings had no significant impacts on subjects.

Watson and Clark (1984) found that positive emotions, like happiness, and negative emotions, such as anxiety and depression, are under the influence of various factors.

Additionally, Nisi and Shahni Yeilagh (2001), to investigate the effect of self-assertiveness training on self-esteem, anxiety, and mental health, randomly selected social anxious male students and divided them into three groups: experimental, placebo, and control. The experimental group participated in 8 sessions of self-assertiveness training. The placebo group discussed various issues which were not related to self-assertiveness and the control group received no interventions. The results of this study demonstrated the effectiveness of self-assertiveness training in improving courage, self-esteem, and mental health and reducing social anxiety.

Hashemi and Latifian (2013) conducted a study aimed to examine the mediating role of test anxiety in relation to perfectionism and procrastination. The findings showed that first, self-oriented and socially-prescribed perfectionism can directly predict academic procrastination. Second, self-oriented perfectionism, compared to socially-prescribed perfectionism, was a strong negative predictor of academic procrastination. Third, test anxiety played a mediating role between perfectionism and academic procrastination. Meanwhile, this role was stronger with regard to socially-prescribed perfectionism. In general, the findings indicated that the mediating role of test anxiety in association with sociallyprescribed perfectionism and procrastination was stronger than its role in self-oriented perfectionism.

\section{Methods and Materials}

This was a descriptive-correlational study. The statistical population of the current study included 4000 female high school students in Zahedan. In the present study, multistage cluster sampling method was used, such that initially high schools were divided into two districts. Then, in each district, 5 high schools were selected randomly. In the next step, in each school, 4 classes were chosen randomly and 9 questionnaires were distributed in each class. Finally, 360 questionnaires were collected. To estimate the sample size in this study, the Morgan table was applied, the result of which considered 350 as the sufficient sample size for 4000 individuals. In this regard, 350 questionnaires were analyzed.

Data was collected through applying three questionnaires as follows.

Beck Anxiety Inventory (BAI): Beck et al. (1988) introduced Beck Anxiety Inventory that specifically measures the severity of clinical anxiety symptoms. Beck Anxiety Inventory is a self-report questionnaire which was developed to examine the severity of anxiety in adolescents and adults.

In Iran, several studies have indicated high reliability and validity of this inventory. Its internal consistency coefficient (alpha coefficient) was 0.92, its reliability, using test-retest method within one week interval, was 0.75 , and correlation of its subscales ranged from 0.30 to 0.76 . Five different types of validity, including content, concurrent, construct, diagnostic, and factor validity, were all used for this inventory to indicate high efficiency of this tool to measure 
the severity of anxiety (Beck et al., 1988).

The rating scale for all of the answers is as follows: not at all (0), mild (1), moderate (2), and severe (3). The scores can range from 0-63.

The Adjustment Inventory of High School Students: This inventory was separately developed by Sinha, from University College of Science Shankar AWKUM, and Singh, from Pantader University in India, to distinguish high school students, aged between 14 and 18 years old, with good adjustment from those with poor adjustment, considering emotional, social, and educational dimensions (Sinha and Singh, 1993, as cited in Karami, 1996). In this study, the final 60 -item questionnaire which can be answered with two options of "Yes" and "No" was used. This test is scored in this way, 0 (adjustment) and 1 (maladjustment). The reliability coefficient of this scale was obtained using split-half, which for the whole scale was 0.95 and for subscales of emotional, social, and educational was respectively $0.94,0.93$, and 0.96 (Rajabi, Chahardoli, Attari, 2007). In the present study, to examine the reliability coefficient, Kuder-Richardson method and split-half were applied, the results of which for the whole scale were 0.81 and 0.70 , and for subscales of emotional, social and educational were respectively 0.66 and $0.64,0.62$ and 0.58 , and 0.67 and 0.58 . The following table shows the distribution of questions and the reliability of this scale.

Table 1: Adjustment, questions and reliability coefficient related to its components

\begin{tabular}{|l|c|c|}
\hline Components & Questions & Kuder-Richardson and split half reliability \\
\hline Emotional & $1-4-7-10-13-16-19-22-25-28-31-34-37-40-43-46-49-52-55-58$ & 0.66 and 0.64 \\
\hline Social & $2-5-8-11-14-17-20-23-26-29-32-35-38-41-44-47-50-53-56-59$ & 0.62 and 0.58 \\
\hline Educational & $3-6-9-12-15-18-21-24-27-30-33-36-39-42-45-48-51-54-57-60$ & 0.67 and 0.58 \\
\hline
\end{tabular}

Academic Procrastination Scale: To investigate procrastination, the Academic Procrastination Scale adopted from Savari (2011) was used. Using multistage cluster sampling method, Savari conducted a study on 247 students of Ahvaz Payame-Noor University. Through applying exploratory factor analysis, a scale including 12 items and 3 factors entitled intentional procrastination (5 items), procrastination resulting from physical-mental fatigue (4 items), and procrastination caused by disorganization ( 3 items) was developed. Applying Cronbach's alpha coefficient, Savari reported that the reliability of the whole scale was 0.85 and for intentional procrastination, procrastination resulting from physical-mental fatigue, and procrastination caused by disorganization, the reliability was respectively $0.77,0.60$, and 0.70 . Moreover, through correlating it with the Takman General Procrastination Test (1991), the validity of this scale was estimated 0.35 . Since this scale is the only inventory in Iran which measures academic procrastination, this scale was used in the current study. In this study, to examine the reliability of the scale, Cronbach's alpha coefficient was used, the results of which indicated that the reliability of the whole scale was 0.89 and the reliability of intentional, physical-mental fatigue, and disorganization was respectively $0.72,0.65$, and 0.74 .

This scale is scored using a Likert-type scale as never (0), rarely (1), sometimes (2), often (3), and always (4). The scores range from 0 to 48 .

The following table represents the distribution of questions and the reliability of the scale.

Table 2: Procrastination, questions, and reliability coefficient related to its components

\begin{tabular}{|l|c|c|}
\hline Components & Questions & Reliability \\
\hline Academic procrastination & $1-2-3-4-5$ & 0.72 \\
\hline Physical-mental fatigue & $6-7-8-9$ & 0.65 \\
\hline Disorganization & $10-11-12$ & 0.74 \\
\hline
\end{tabular}

The obtained data was analyzed in two levels of descriptive (including frequency, tables, percentage, mean and standard deviation) and inferential statistics containing Pearson correlation coefficient. It should be noted that all statistical test were conducted via SPSS 19 .

\section{Descriptive Data}

In this section, data on the demographic characteristics of respondents is provided. 
Table 3: Results of frequency distribution based on field of study

\begin{tabular}{|l|c|c|c|c|c|}
\hline Field of study & Mathematics & Science & Humanities & Technical and Vocational & Work and Knowledge \\
\hline Percent & 16.7 & 19.4 & 26.4 & 22.2 & 15.3 \\
\hline Frequency & 58 & 68 & 92 & 78 & 54 \\
\hline
\end{tabular}

The results demonstrated in this table indicate that $16.7 \%$ of students were mathematics students, $19.4 \%$ of them were science students, $26.4 \%$ of them were humanities students, $22.2 \%$ of them were students of the technical and vocational fields and $15.3 \%$ of them were students of the work and knowledge fields.

\section{Results}

First Question: Is there any significant relationship between anxiety among female high school students in Zahedan and their adjustment?

Table 4: Results of Pearson correlation coefficient test for anxiety and adjustment

\begin{tabular}{|l|c|c|}
\hline Component & Adjustment & Sig \\
\hline Anxiety & 0.68 & 0.001 \\
\hline
\end{tabular}

The results demonstrated in Table 4 show that the correlation coefficient between adjustment, in general, and anxiety among students is 0.68 , indicating a statistically direct and significant relationship at the $99 \%$ confidence level.

Second Question: Is there any significant relationship between anxiety among female high school students in Zahedan and their emotional adjustment?

Table 5: Results of Pearson correlation coefficient test for anxiety and emotional adjustment

\begin{tabular}{|l|c|c|}
\hline Component & Emotional Adjustment & Sig \\
\hline Anxiety & 0.73 & 0.001 \\
\hline
\end{tabular}

The results presented in Table 5 indicate that the correlation coefficient between emotional adjustment and anxiety among students is 0.73 , demonstrating a statistically direct and significant relationship at the $99 \%$ confidence level.

Third Question: Is there any significant relationship between anxiety among female high school students in Zahedan and their social adjustment?

Table 6: Results of Pearson correlation coefficient test for anxiety and social adjustment

\begin{tabular}{|l|c|c|}
\hline Component & Social Adjustment & Sig \\
\hline Anxiety & 0.57 & 0.001 \\
\hline
\end{tabular}

The results presented in Table 6 demonstrate that the correlation coefficient between social adjustment and anxiety among students is 0.57 , showing a statistically direct and significant relationship at the $99 \%$ confidence level.

Fourth Question: Is there any significant relationship between anxiety among female high school students in Zahedan and their educational adjustment?

Table 7: Results of Pearson correlation coefficient test for anxiety and educational adjustment

\begin{tabular}{|l|c|c|}
\hline Component & Educational Adjustment & Sig \\
\hline Anxiety & 0.36 & 0.001 \\
\hline
\end{tabular}

The results demonstrated in Table 7 indicate that the correlation coefficient between educational adjustment and anxiety among students is 0.36 , representing a statistically direct and significant relationship at the $99 \%$ confidence level.

Fifth Question: Is there any significant relationship between anxiety among female high school students in Zahedan and their procrastination? 
Table 8: Results of Pearson correlation coefficient test for anxiety and procrastination

\begin{tabular}{|l|c|c|}
\hline Component & Procrastination & Sig \\
\hline Anxiety & 0.505 & 0.001 \\
\hline
\end{tabular}

The results presented in Table 8 indicate that the correlation coefficient between procrastination, in general, and anxiety among students is 0.505 , showing a statistically direct and significant relationship at the $99 \%$ confidence level.

Sixth Question: Is there any significant relationship between anxiety among female high school students in Zahedan and their intentional procrastination?

Table 9: Results of Pearson correlation coefficient test for anxiety and intentional procrastination

\begin{tabular}{|l|c|c|}
\hline Component & Intentional procrastination & Sig \\
\hline Anxiety & 0.20 & 0.001 \\
\hline
\end{tabular}

The results demonstrated in Table 9 show that the correlation coefficient between intentional procrastination and anxiety among students is 0.20 , indicating a statistically direct and significant relationship at the $99 \%$ confidence level.

Seventh Question: Is there any significant relationship between anxiety among female high school students in Zahedan and their procrastination resulting from physical-mental fatigue?

Table 10: Results of Pearson correlation coefficient test for anxiety and procrastination resulting from physical-mental fatigue

\begin{tabular}{|l|c|c|}
\hline Component & Physical-mental fatigue & Sig \\
\hline Anxiety & 0.48 & 0.001 \\
\hline
\end{tabular}

The results shown in Table 10 indicate that the correlation coefficient between procrastination resulting from physicalmental fatigue and anxiety among students is 0.48 , showing a statistically direct and significant relationship at the $99 \%$ confidence level.

Eighth Question: Is there any significant relationship between anxiety among female high school students in Zahedan and their procrastination caused by disorganization?

Table 11: Results of Pearson correlation coefficient test for anxiety and procrastination caused by disorganization

\begin{tabular}{|l|c|c|}
\hline Component & Disorganization & Sig \\
\hline Anxiety & 0.68 & 0.001 \\
\hline
\end{tabular}

The results presented in Table 11 demonstrate that the correlation coefficient between procrastination caused by disorganization and anxiety among students is 0.68 , showing a statistically direct and significant relationship at the $99 \%$ confidence level.

\section{Discussion and Conclusion}

First Question: Is there any significant relationship between anxiety among female high school students in Zahedan and their adjustment?

The results of Pearson correlation coefficient indicated that anxiety among students was significantly and directly related to students' adjustment. This is in line with the results of some previously conducted studies on the issue including Watson and Clark (1984) and Tozandejani et al. (2007).

Second Question: Is there any significant relationship between anxiety among female high school students in Zahedan and their emotional adjustment?

The results of Pearson correlation coefficient showed that anxiety among students was significantly and directly related to their emotional adjustment. This finding is consistent with the results of Sabeti and Shahni Yeilagh (1998) and Shahni Yeilagh, Majidi, and Haghighi Mobarake (2002).

Third Question: Is there any significant relationship between anxiety among female high school students in 
Zahedan and their social adjustment?

The results of Pearson correlation coefficient demonstrated that anxiety among students was significantly and directly correlated with their social adjustment. This result is in line with the results of a similar study conducted by Taghipour et al. (2012).

Fourth Question: Is there any significant relationship between anxiety among female high school students in Zahedan and their educational adjustment?

The results of Pearson correlation coefficient showed that anxiety among students was significantly and directly correlated with their educational adjustment. This finding is consistent with the results of a similar study carried out by Shahni Yeilagh, Majidi, and Haghighi Mobarake (2012).

Fifth Question: Is there any significant relationship between anxiety among female high school students in Zahedan and their procrastination?

The results of Pearson correlation coefficient demonstrated that anxiety among students was significantly and directly correlated with their procrastination. This finding is in line with the results of similar studies conducted by Hashemi and Latifian (2013) and Farran (2004).

Sixth Question: Is there any significant relationship between anxiety among female high school students in Zahedan and their intentional procrastination?

The results of Pearson correlation coefficient demonstrated that anxiety among students was significantly and directly correlated with their intentional procrastination. This result is in line with the results of studies conducted by Farran (2004) and Essau, Ederer, Ocallaghan, and Ashemann (2008).

Seventh Question: Is there any significant relationship between anxiety among female high school students in Zahedan and their procrastination resulting from physical-mental fatigue?

The results of Pearson correlation coefficient showed that anxiety among students was significantly and directly related to their procrastination resulting from physical-mental fatigue. This finding is consistent with the results of a study carried out by Vodanovich and Rupp (1999).

Eighth Question: Is there any significant relationship between anxiety among female high school students in Zahedan and their procrastination caused by disorganization?

The results of Pearson correlation coefficient demonstrated that anxiety among students was significantly and directly related to their procrastination caused by disorganization. This is consistent with the results of a study carried out by Essau, Ederer, Ocallaghan, and Ashemann (2008).

In this regard, it can be concluded that there was a significant and direct correlation between anxiety among students and their adjustment. Respectively, anxiety was strongly related to emotional adjustment, was then correlated with social adjustment, and was finally related to students' educational adjustment, indicating that anxiety and students' mental health play significant roles in their adjustment. Additionally, other results demonstrated that anxiety among students was significantly and directly related to their procrastination. Anxiety among students had the highest correlation with procrastination caused by disorganization and it had the lowest correlation with students' intentional procrastination. This put an emphasis on the importance of anxiety and providing essential trainings to control anxiety among adolescents.

\section{References}

Alice, A., \& Jamesnal, W. (2003). The psychology of procrastination: Overcoming procrastination. Translate by: Farjad, M.A., Tehran: Roshd Publication.

Beck, A. T., Epstein, N., Brown, G., \& Steer, R. (1988). An inventory- for measuring clinical anxiety: Psychometric properties. Journal of Consulting and Clinical Psychology, 56, 893-897.

Essau, C. A., Ederer, E. M., Ocallaghan, J., \& Ashemann, B. (2008). Doing it now or later? A poster presentation at the presentation at the $8^{\text {th }}$ Alps-Adria psychology Conference, October 2-4, Ljubljana, Slovenia.

Farran, B. (2004). Predictors of academic procrastination in college students. Unpublished doctoral dissertation, Fordham University, New York.

Hashemi, L., \& Latifian, M. (2013). Perfectionism and Procrastination Study: Study of the mediating role of anxiety. Journal of Personality and Individual Differences, 2(3), 73-99.

Hawton, K., Salkovskis, P., Kirk, J., \& Clark, D. (1989). Cognitive behavioral therapy for psychiatric problems: A practical guide for mental disorders treatment. $1^{\text {st }}$ Edition. Translated by: Ghasemzadeh, H., Tehran: Arjman Publication.

Karami, D. (2009). The prevalence of anxiety and procrastination in students and its association with depression and anxiety. Thoughts and Behavior, 4(13), 25-35.

Krnig, A.M., Davison, G.C. Neil, J. M., J., \& Sherry, L. (2007). Psychopathology, abnormal psychology. Translated by: Shamsipour H., 
Tehran: Arjmand publication.

Maslow, A.H. (2000). Self-Actualization and Beyond in G.F.T. challenges of Humanistic psychology. New York: McGraw Press.

Nisi, A.A., \& Shahni Yeilagh, M. (2001). The effect of self-assertion training on self-assertion, self-esteem, social anxiety, and mental health of anxious male high school students in Ahvaz. Journal of educational Sciences and Psychology, Shahid Chamran University of Ahvaz, 3(8), 11-30.

Pope, W. A., Machale, M.S., \& Edward, W. (1999). Self-esteem enhancement with children and Adolescents. New York: Pergamon Press.

Rajabi, Gh. R., Chahardoli, H., \& Attari ,Y. (2009). The relationship between family functioning and psychological-social climate class with maladjustment high school students. Journal of Chamran University of Educational Sciences and Psychology, 1(2), 128113.

Sabeti, F., \& Shahni Yeilagh, M. (1998). The impact of social skills training in reducing social- emotional maladjustments among male elementary school students in Ahvaz. Journal of Education and Psychology, University of Shahid Chamran, 3(3-4), 1-16.

Sadeghian, E., \& Heidarianpour, A. (2009). Determination of mental health and related stressors in student of Hamadan medical university. The Hayat official scientific quarterly publication of the School of Nursing \& Midwifery, 15(1), 71-81.

Savari, K. (2011). Construction and validation of academic procrastination test. Journal of Educational Measurement, 5(2), 97-110.

Shahni Yeilagh, M., Majidi, R., Haghighi Mobarake, J. (2012). Causal relationship of general intelligence and emotional intelligence with academic performance with the mediation of test anxiety and adjustment in first-year high school students in public high schools of Boroujerd, Journal of Teaching and Learning, 4(1), 75-104.

Singh, R. P., \& Sinha, A. K. P. (1993). The Adjustment Inventory for school students (AISS). Agra: National Psychological Corporation.

Sutton, J. (2009). Avoid procrastination. Urges action now, not later. Ferrari, J. R., Jonson, J.L., \& McCown, W.G., Procrastination and task avoidance: theory research and treatment. New York: Plenum Press.

Taghipour, A., Ghaffari, M., Samdaliri, A., \& Farzi, F. (2013). The effectiveness of cognitive-behavioral training on reducing anxiety and social adjustment of students. Psychological Research, 6(24), $43-57$.

Tozandehjani, H., Sedighi, K., Nejat, H., Kamalpour, N. (2007). Relative Effectiveness of cognitive-behavioral and self-esteem trainings on social adjustment of students. Research in Curriculum Development, 21(16), 41-56.

Vodanovich, S. J., \& Rupp, D., E. (1999). Are procrastinators prone to bored on? Social Behavior \& Personality, 27(1), 11- 16.

Watson, D., \& Clark, L. A. (1984). Negative Affectivity: The disposition to experience aversive emotional states. Psychological Bulletin, 96, 465-490. 